\title{
Effects of Heat Treatment by Immersion in Household Conditions on Olive Oil as Compared to Other Culinary Oils: A Descriptive Study
}

\author{
Carlos A. Nogueira-De-Almeida ${ }^{a^{*}}$ and Geórgia A. de Castro ${ }^{b}$ \\ ${ }^{\text {a }}$ Federal University of São Carlos (UFSCAR), Medical Department, Rod. Washington Luiz, km 235, São \\ Carlos, SP, Brazil \\ b University of Campinas, Cidade Universitária Zeferino Vaz, Campinas, SP, Brazil \\ ${ }^{*}$ Corresponding author \\ dr.nogueira@me.com \\ TEL: +55 1638775034
}

Received: 30 May 2017; Published online: 18 April 2018

\begin{abstract}
The objectives were to evaluate the properties of refined (ROO) and extra-virgin olive oil (EVOO) in their natural state (fresh) and after heating, while comparing them with each other and with refined soybean (SBO) and refined sunflower seed oil (SFO). The methodology was designed to simulate, in controlled laboratory conditions, the home-frying process, while evaluating fatty acid profile (fatty acid methyl esters were separated by gas chromatography), concentration of phenolic compounds (Gallic acid dosage), antioxidant activity (DPPH), and production of polar compounds (thin layer chromatography) before and after heating to $200{ }^{\circ} \mathrm{C}$ for six minutes. It was observed that, before and after heating, SBO and SFO are rich in polyunsaturated fatty acids (FA) and ROO and EVOO are rich in monounsaturated FA. Fresh or heated, ROO and EVOO do not have trans FA, which are present in SBO and SFO, and increase in SBO after heating $(+32.8 \%)$. The concentrations of phenolic compounds are always higher in olive oils, despite the decrease that occurs after heating $(-7.5 \%$ in the ROO and $-24.6 \%$ in EVOO). Antioxidant activity is greater when olive oils are fresh and remains present in EVOO after heating. The concentration of polar compounds was similar for all oils after heating. In conclusion, ROO and EVOO are the richest in monounsaturated FA even after heating, with no production of saturated or trans FA. Despite losing some antioxidant activity, heated EVOO remains richer in monounsaturated FA than ROO, SBO and SFO in the fresh version. All oils suffer similar rates of degradation.
\end{abstract}

Keywords: Olive Oil; Thermic Treatment; Oxidation stability; Phenolic Compounds; Mediterranean Diet; Oils

\section{Introduction}

Vegetable oils are widely used in home food preparation, either fresh as seasoning of cold dishes or added to the preparations that will be cooked, baked or fried by immersion. Oils from different sources such as olive, soybean, sunflower seed, canola and corn germ, among others can be found in the market, and the composition of each has differences that can impact the user's health. In respect to olive oil, studies conducted over the past few decades have demonstrated many health benefits due to the high content of oleic acid (18:1n-9), and the presence of $\alpha$-linolenic acid (18:3n-3), antioxidants and free radical scavengers (Guasch-Ferre et al., 2014; Schwingshackl, Christoph, \& Hoffmann, 2015; Schwingshackl \& Hoffmann, 2014a, 2014b). 


\section{Nomenclature}

ROO refined olive oil

EVOO extra-virgin olive oil
SBO

soybean oil

SFO

sunflower seed oil

There are several different presentations of olive oil in the market. Extra-virgin is obtained from the fruit of the olive tree (Olea europea L.) by mechanical means only, without any treatment other than washing, filtrating, decanting, and centrifuging (Codex, 2015). The minor components from the olive fruit, including phenolic compounds remain in the final product, unlike other vegetable oils that are subjected to refining processes (Ballus, 2014; Shahidi \& Zhong, 2005). The non-extra virgin olive oil is a blend of refined olive oil and virgin olive oil. The "Mediterranean" food standard, recognized by science as one of the healthiest, has in olive oil one of its main components, according to the Second International Conference on Olive Oil and Health (Lopez-Miranda et al., 2010). The main benefits of this food recognized by science are: it reduces LDL-cholesterol (LDL-c), increases HDLcholesterol (HDL-c)/LDL-c, reduces LDL-c oxidability, improves glucose metabolism, helps blood pressure control and endothelial function, promotes antithrombotic environment, has a favorable effect against obesity, promotes less activation of fasting and post prandial nuclear factor kappa-light-chain-enhancer of activated B cells (NF-KB), reduces age-related cognitive decline and Alzheimer's disease (Lopez-Miranda et al., 2010).

In Brazil, the olive oil consumption of about 200 milliliters per capita per year is quite low as compared to other countries. In Greece it is 26 liters, in Spain 12 liters, and in Portugal 7 liters (Nogueira-de-Almeida, Ribas Filho, de Mello, Melz, \& Almeida, 2015). One possible reason for this low consumption is the combination of high price compared to other vegetable oils, and the idea that its use should be restricted to finishing cold dishes. There is, in fact, the belief that, once heated, olive oil would suffer changes in its lipid profile, thereby degrading and losing its beneficial health properties. Additionally, even recognizing that olive oil may be the best option when used fresh, it is commonly believed that after heating, it becomes worse than other oils in relation to nutritional quality (Nogueira-de-Almeida et al., 2015). Oil can be heated in many ways, but the most common process is by frying, which leads to multiple reactions that generate mostly non-volatile, chemical compounds, i.e., they remain in the oil, affecting their physical properties (Katragadda, Fullana, Sidhu, \& Carbonell-Barrachina, 2010). The quality of the foods cooked by this method is dependent on: frying conditions, temperature, time, type of food, and volume and type of oil used (Katragadda et al., 2010). The formation of aldehydes and volatile compounds during frying depends mainly on the process temperature. The trend towards the production of volatile compounds also depends on the fatty acids' composition (Katragadda et al., 2010). Heating also modifies many properties of oils, such as the profile of fatty acids, antioxidant capacity, and nutritional quality (Nogueira-de-Almeida et al., 2015; Valderas-Martinez et al., 2016). Some of these can be evaluated by laboratory indicators, such as the composition of fatty acids, the antioxidant capacity, the amount of phenolic compounds, and degradation (Allouche, Jimenez, Gaforio, Uceda, \& Beltran, 2007; Ballus, 2014; Cicerale, Conlan, Sinclair, \& Keast, 2009; Daskalaki, Kefi, Kotsiou, \& Tasioula-Margari, 2009; Freire, Ferreira, \& Mancini-Filho, 2013; Nunes, de Souza, Correa, \& da Costa e Silva, 2013; Santos, Cruz, Cunha, \& Casal, 2013). This study intended to describe properties of two types of olive oil in their natural state and after heating at home- 
Effects of heat treatment on olive oil $\mid 91$

frying simulation, while comparing them to other oils used for cooking.

\section{Methods}

Four options of the most used oils for home cooking in Brazil were defined for the study: refined olive oil (ROO), characterized as a blend of refined olive oil and virgin olive oil; extra-virgin olive oil (EVOO) characterized as a mixture of extra-virgin olive oils; refined soybean oil (SBO) and refined sunflower seed oil (SFO).

Some parameters were defined considering that the main objective of the study was to evaluate the effects of heat treatment: temperature, type, and duration of heating. We chose to mimic, in controlled laboratory conditions, the process of home-frying, since it is one of the most common and more drastic heat treatment used in food preparation. Therefore, we researched products available in the Brazilian market that indicated on the label their suitability for frying and manufacturer's instructions on the correct way of preparation. Temperature and heating time were set at $200{ }^{\circ} \mathrm{C}$ for 6 minutes, an estimated average time to prepare 1 portion of food used as a reference: potatoes, nuggets, chicken fingers, fish, squid, croquette, polenta, meat, churros, and vegetables. These products were used only to obtain references for the methodology. The trials were conducted only with the oils, and no foods were prepared.

About 5 liters of oil were used for each heat treatment. All samples were obtained, by donation or purchased in supermarkets in the city of São Paulo, within the expiration date as described by the manufacturers on the label. The same batch as described by the manufacturer on the label was used for each sample, which were coded with 3 non-sequential and random numbers, making it impossible to identify them at the time of the analytical methodology. The samples were weighed, and after setting the fryer to $200{ }^{\circ} \mathrm{C}$ they were deposited into the tanks and the temperature monitored to reach the target value of the heat treatment. The temperature was measured for each sample at time zero, and thereafter at every minute until reaching 200
${ }^{\circ} \mathrm{C}$. Once the target temperature was reached, it was measured every minute to establish the specific range of the heat treatment of each sample as detailed in Table 1. After the heat treatment, the samples were immediately placed in amber vials with no head-space in order to prevent oxidation, and cooled in a freezer until the temperature reached below $-10{ }^{\circ} \mathrm{C}$.

Determination of fatty acids was carried out on a single sample of each oil, and the other tests in a set of three. All measurements were performed at the Instituto de Tecnologia de Alimentos (Food Technology Institute) (ITAL) of the State of São Paulo, with the exception of the polar compounds, which were measured by the Oils and Fats Laboratory of the Food Engineering School of Unicamp.

The following properties were measured before and after heat treatment for each sample:

Antioxidant activity: determination of antioxidant activity based on the ability of the sample to reduce 2,2-diphenyl-1picrylhydrazyl (DPPH) radical, as described by Brand-Williams, Cuvelier, and Berset (1995).

Phenolic compounds: Concentration of phenolic compounds expressed as gallic acid equivalents, as proposed by Kim, Chun, Kim, Moon, and Lee (2003).

Determination of fatty acid composition: Conducted according to the Ce 1a-13 methodologies, CE 1h-05 and 996.06 of the American Oil Chemists' Society (American Oil Chemists' Society, 2009).

\section{Determination of polar compounds:}

Column chromatography using methodology standardized by the American Oil Chemists' Society (2009).

\section{Results and Discussion}

The results were expressed using the fresh values, in the case of fatty acids (in which only one 
Table 1: Conditions of Heat Treatment

\begin{tabular}{lll}
\hline Samples & $\begin{array}{l}\text { Time to reach the } 200^{\circ} \mathrm{C} \\
\text { goal temperature }\end{array}$ & $\begin{array}{l}\text { Temperature variation during heat } \\
\text { treatment of } 200^{\circ} \mathrm{C} \text { for } 6 \text { minutes }\end{array}$ \\
\hline Soybean oil & 5 minutes and 21 seconds & $201.97^{\circ} \mathrm{C} \pm 2.13$ \\
Sunflower seed oil & 6 minutes and 3 seconds & $200.9^{\circ} \mathrm{C} \pm 1.72$ \\
Refined olive oil & 6 minutes and 16 seconds & $199.27^{\circ} \mathrm{C} \pm 2.08$ \\
Extra-virgin olive oil & 5 minutes and 22 seconds & $200.47^{\circ} \mathrm{C} \pm 1.78$ \\
\hline
\end{tabular}

sample of each oil was measured), and as means and standard deviations for phenolic compounds, gallic acid and polar compounds (where determination was performed on three samples of each type of oil), being grouped in tables. A comparison between the characteristics of each of the oils at time zero and after heat treatment was presented in a descriptive way.

\subsection{Results}

The results are depicted in Tables 2 and 3 .

Table 2 demonstrates that the four oils studied are different in their composition when fresh, and the differences remain after heating. SFO is the poorest in saturated fatty acids and this profile persists after heating. Olive oils (ROO and EVOO) are the richest in monounsaturated fatty acids and this profile also remains after heating. SBO and SFO are quite rich in polyunsaturated fatty acids, and SBO is especially rich in omega-3, and this profile persists after heating. There is also little change in the saturated fatty acid profile after heating, although for EVOO the amount is reduced. There is also little change in the monounsaturated fatty acid profile, although for EVOO the concentration increases. There is little change in the polyunsaturated fatty acid profile, although for EVOO there is a reduction in levels of both omega-3 and omega-6. It is important to state that this is a descriptive study, so we did not conduct statistical analysis that would be relevant to support the findings.

When fresh, olive oils have no trans fatty acids, although they are found in SBO and SFO. After heating, olive oils still do not contain trans fatty acids but they increase in amount in SBO and remain present in SFO.
The quantities of phenolic compounds are much higher in olive oils and this difference remains after heating. This process decreases the amount of these compounds in olive oils (loss of $7.5 \%$ in ROO and $24.6 \%$ in EVOO), and they become undetectable in SBO and SFO. Even considering the decrement in phenolic compounds, heated olive oils are still richer in these compounds than $\mathrm{SBO}$ and SFO in the fresh version.

The antioxidant activity evaluated by the DPPH method is greater in fresh olive oils and remains significant for EVOO after heating. SBO and SFO have no antioxidant activity, neither before nor after heating. Olive oils lose their antioxidant activity upon heating ( $100 \%$ for ROO and $26.6 \%$ for EVOO). Even considering the loss of antioxidant activity, heated EVOO is still richer in these compounds than ROO, SBO and SFO in the fresh version.

The results for the polar compounds demonstrate that all oils suffer some degree of degradation and although having different concentrations of polar compounds when fresh, after heating the values are very similar.

Table 3 depicts the individual fatty acids. The profile of SBO and SFO differs significantly from olive oils. The omega-9 content is $66 \%$ less for SBO and $47 \%$ less for SFO than for both olive oils.

Some qualitative results on the characteristics of the samples during the heat treatment have to be underscored: SBO and SFO caused a burning sensation on the researcher's eyes during the frying test, possibly due to the production of acrolein (Beauchamp, Andjelkovich, Kligerman, Morgan, \& Heck, 1985) and this was more intense with SBO. ROO hardly caused any discomfort. EVOO caused a perception of burning in the mucosa of the digestive tract, possibly due 
Effects of heat treatment on olive oil $\mid 93$

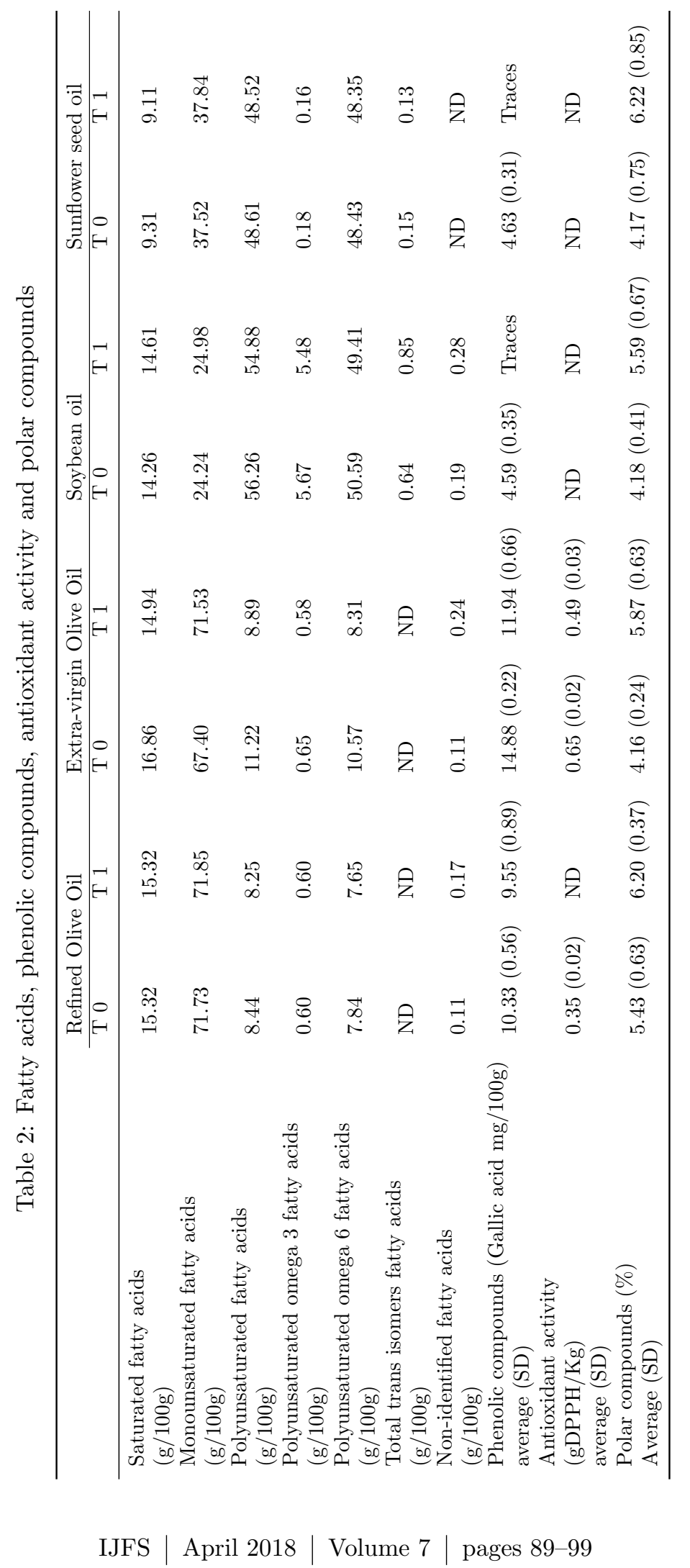




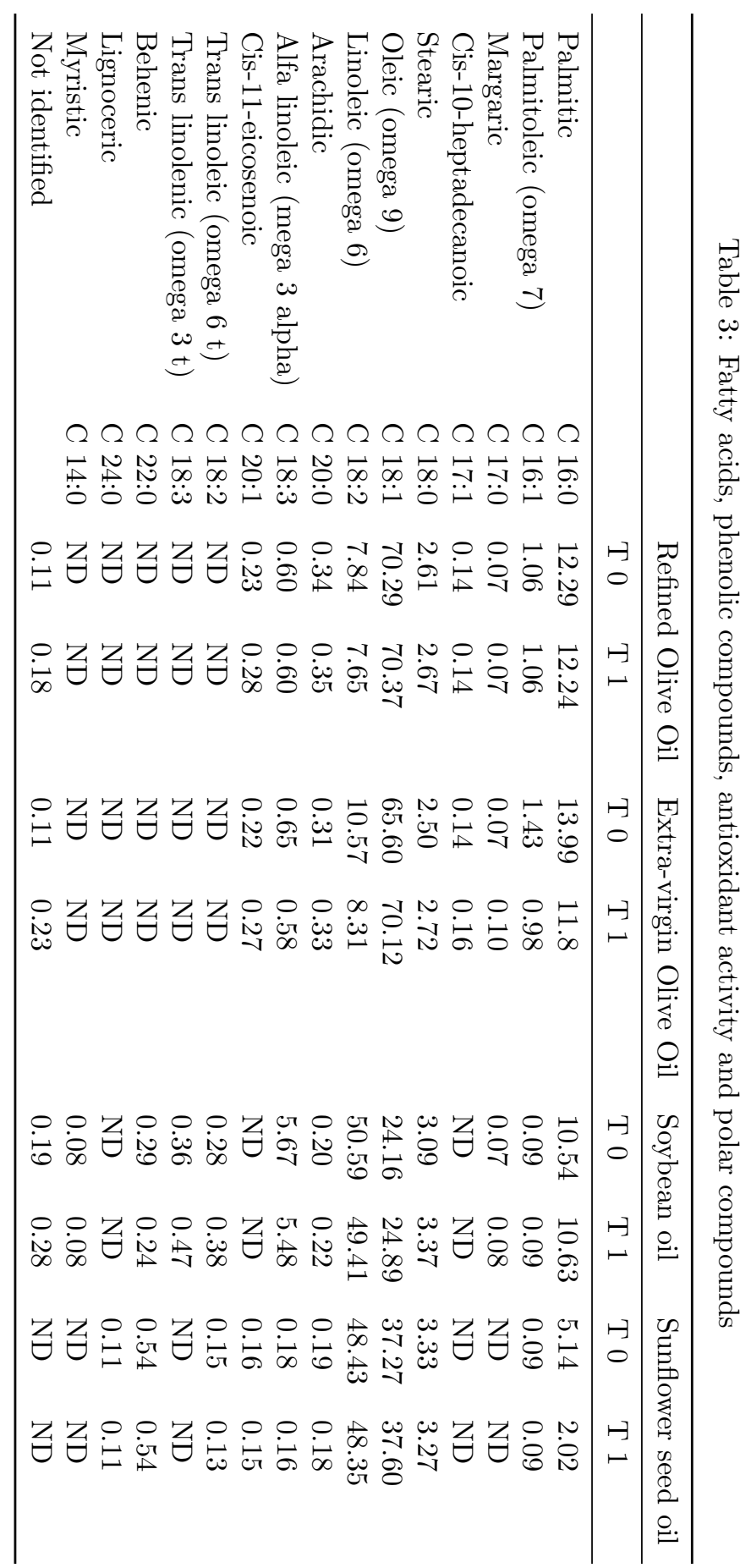

IJFS | April 2018 | Volume 7 | pages 89-99 
to volatilization of spicy compounds which are typical of this type of product.

Although many oils are used in industry, often in extreme temperature conditions, it is important to understand how they behave in household use and thus provide health professionals with results that can help educate their patients.

Data presented in this study were obtained simulating household conditions and it is worth remembering that the experiments were conducted only once under controlled temperature and time. It is known that if the same oil is used repeatedly for frying, its properties are progressively lost and there is the risk of occurrence of toxic by-products (Freire et al., 2013).

The fatty acids' profile directly affects the sensory properties of oils in the parameters of texture and melting point, which impacts on the stability of the oil oxidation when exposed to light and oxygen during the shelf life of the product. Saturated fatty acids increase the melting point, providing firmer texture than polyunsaturated and monounsaturated acids, even when the oil is in liquid form. In this study, the oil with the lowest percentage of saturated fatty acids was SFO, which possibly gives it a lower melting point. The high content of oleic acid in olive oil is important because it is less susceptible to oxidation than polyunsaturated fatty acids, which predominate in other oils, therefore contributing to its stability (Owen et al., 2000). It also helps to reduce serum levels of LDL cholesterol and increase HDL cholesterol. $\alpha$-linolenic acid (ALA, 18:3n-3) helps reduce the risk of heart disease, decreases blood pressure, and protects against the formation of plaques in the arteries (Cicerale et al., 2009).

Many metabolic reactions that occur physiologically in the human body cause reduction of molecular oxygen releasing reactive species known as free radicals. Due to the damage caused by such radicals in the metabolism and induction of various diseases, they must be inactivated. That role is played by antioxidants which can either be produced by the body or ingested in the diet. One way to evaluate the antioxidant capacity of oils is by the DPPH method. In this study and by this method, SBO and SFO did not show antioxidant activity, not even when fresh. Refined olive oil ex- hibited antioxidant activity only before heating but EVOO exhibited antioxidant activity before and after heating, with greater activity than the other oils even after being heated. Phenolic compounds such as gallic acid, which was measured in this study, are among the antioxidants found in plant foods. These compounds can reduce blood pressure and protect against the formation of atheroma plaques (Cicerale et al., 2009). EVOO is not refined, therefore containing many unsaponifiable compounds, especially phenols, which would generally be removed by refining (Caruso et al., 1999; Ragazzi \& Veronese, 1973). In fact, the data demonstrated that gallic acid is present in olive oils, in higher amounts in EVOO and, after heating, can still be found in quantities higher than in the other oils studied even when fresh. Fresh SBO and SFO contain gallic acid and may, therefore, be considered as having an antioxidant effect but, when heated, even at a home process temperature and for a short time, completely lose this property. The phenolic compounds of olive oils have shown higher antioxidant properties than vitamin $\mathrm{E}$ in lipids and in DNA oxidation in vitro and ex vivo (Fitó et al., 2007). They are also able to prevent endothelial dysfunction, decreasing the expression of cell adhesion molecules and increasing the production of nitric oxide (Fitó et al., 2007). In addition, they inhibit platelet aggregation and improve the mRNA transcript of the antioxidant enzyme glutathione peroxidase (Fitó et al., 2007). Other potential activities include anti-inflammatory chemopreventive activity and delay in the progression of atherosclerosis (Fitó et al., 2007). Phenolic compounds play an important role in the quality of olive oils, as they contribute significantly to the oxidative stability. EVOO has remarkable resistance to oxidation, which has been related to its composition in fatty acids and high levels of natural antioxidants such as phenolic hydrophilic and lipophilic compounds (Papadimitriou et al., 2006).

Other authors have investigated the effect of heat on edible oils. Daskalaki et al. (2009) found that by frying at a temperature of $180^{\circ} \mathrm{C}$ there was a $60 \%$ reduction of phenolic compounds (hydroxytyrosol derivatives) in EVOO after 30 minutes. At $100{ }^{\circ} \mathrm{C}$ for 2 hours, the decrement was of less than 20\%. Amati et al. (2008) also observed 
partial degradation of phenolic compounds in EVOO, but only at $180{ }^{\circ} \mathrm{C}$. Sánchez-Muniz and Bastida (2006) considered that olive oils are the most suitable for frying because they are more resistant to heat oxidation. Santos et al. (2013) stated that, even recognizing loss of antioxidant properties, EVOO is the most stable household oil, but emphasized that it is important not to expose it to excessive temperatures, especially for long periods, which could lead to loss of its properties. Allouche et al. (2007) evaluated the decrement of antioxidants in olive oil and found that tocopherol and polyphenol were the most affected by heat treatment and decreased the most. Sanchez-Gimeno, Negueruela, Benito, Vercet, and Oria (2008) when comparing the behavior of olive oil to SFO concluded that, during frying, olive oil was the more stable to an oxidative process and was able to sustain its rich oleic acid composition. Allouche et al. (2007) found that the concentration of oleic acid, the most abundant fatty acid in olive oil, does not change with the duration of heating. Penz (2010) reported that the lipid profile of olive oil suffers little change after heat treatment. Furthermore, according to these authors, heating does not lead to a loss of phytosterol; on the contrary, the levels may increase. This may be due to an increased solubility of these compounds with increasing temperature.

The evaluation of oil degradation after heat treatment can be done by checking the production of polar compounds, which are derived from oxidation, hydrolysis or other degradation processes. Those are compounds present in the hydrophilic phase of oil, which is unwanted, since it is an oil-based product (lipophilic). The quantification of polar compounds has been the most efficient method to measure the quality of oils (Carapinha, 2012). In Portugal, for example, legislation sets the value of $25 \%$ as the maximum allowed in the oils used for frying (Carapinha, 2012). The assessment is made by the total content of these compounds, whose formation is strongly related to the primary and secondary stages of oxidation, demonstrating the oil degradation (Kalantzakis, Blekas, Pegklidou, \& Boskou, 2006). The oily phase, hydrophobic, must be the major and almost total composition of oils. The results of this study demonstrate that polar compounds already appear in the fresh version at least for ROO, SBO and SFO, and may have been formed during the refining process, which includes heating steps. After the frying tests, it was noted that the 4 oils had similar concentrations of polar compounds, which demonstrates some degree of degradation always occurs when they are heated. Dobarganes (1992) found that when compared to other oils commonly used (sunflower seed, soybean, and palm oil), olive oils are the most stable, with less production of polar compounds after five hours of thermal oxidation and even after being used 15 times for frying. The fatty acid composition of olive oils favors oxidation stability, generating less polar compounds while maintaining the integrity of the lipophilic phase naturally present in olive oils. If foods were to be fried in the oils during heat treatment, the amounts of polar compounds would be different due to the water activity of the food, oil absorption and food temperature before being added to the fryer. Likewise, if the oils had been tested in successive frying, the results of polar compounds would possibly rise according to the number of re-uses (Freire et al., 2013).

In order to make recommendations based on the available scientific evidence, some authors draw conclusions about olive oil. Sacchi, Paduano, Savarese, Vitaglione, and Fogliano (2014) considered olive oil as the best option for food preparation, after observing that heating it hardly led to the production of toxic products such as acrylamide and, even when considering this possibility, the antioxidants present in olive oil would inhibit its formation. Dobarganes (1992) considered that, in the fresh version, olive oil is the best choice, especially for its organoleptic characteristics; for frying, it would also be the best option, due to its greater stability.

This is a descriptive study, which is its main limitation. The tests were made in a single sample of each type of oil or at the most in three samples, therefore statistical analysis was not possible. However, in the absence of similar studies in oils marketed in Brazil, the present data can serve as foundation for future research. Additionally, the researchers chose to conduct a descriptive study, considering the budget available to include more indicators at the expense of more samples. Another limitation is the fact that food 
Effects of heat treatment on olive oil $\mid 97$

was not used (only the oils were heated) and this is an important issue, because the presence of moisture in the food is quite relevant during the frying process. With the inclusion of food, the process could approach that of real cooking, but on the other hand, variables related to the chosen food would be introduced and the results could not be generalized. The option therefore was for a strictly experimental study, bringing concrete information on the behavior of the oil itself.

\section{Conclusions}

The heating tests of this study, in conditions similar to home-frying, demonstrated that ROO and EVOO are the richest in monounsaturated fatty acids and that they retained this profile after heating, without any observed formation of saturated fatty acids. When fresh, ROO and EVOO have no trans fatty acids but these are present in SBO and SFO. After heating, ROO and EVOO also contain no trans fatty acids but they increase in amount in SBO and remain present in SFO. The quantities of phenolic compounds are higher in ROO and EVOO and this difference remains after heating. Even considering the loss of antioxidant activity, the heated EVOO is still richer in these compounds than $\mathrm{ROO}$ and SBO, and SFO in the fresh version. All oils suffer some degree of degradation and, whilst containing different concentrations of polar compounds when fresh, they have similar amounts after heating.

\section{References}

Allouche, Y., Jimenez, A., Gaforio, J. J., Uceda, M., \& Beltran, G. (2007). How heating affects extra virgin olive oil quality indexes and chemical composition. Journal of Agricultural and Food Chemistry, 55(23), 96469654. doi:10.1021/jf070628u

Amati, L., Campanella, L., Dragone, R., Nuccilli, A., Tomassetti, M., \& Vecchio, S. (2008). New investigation of the isothermal oxidation of extra virgin olive oil: determination of free radicals, total polyphenols, total antioxidant capacity, and kinetic data. Journal of Agricultural and Food Chemistry, 56(18), 8287-8295. doi:10.1021/jf8011695
American Oil Chemists' Society. (2009). Official methods and recommended practices of the aocs (6th ed.) Retrieved from https: / / www . aocs . org / info / 6th - edition / 6thedition

Ballus, C. A. (2014). Chemical characterization and antioxidant capacity of extra-virgin olive oils from brazil and other countries using electrophoretic, chromatographic and spectrometric techniques (Doctoral dissertation, Unicamp, Brazil). Retrieved from http : / / repositorio . unicamp . br / jspui / handle/REPOSIP / 254308

Beauchamp, R. O., Andjelkovich, D. A., Kligerman, A. D., Morgan, K. T., \& Heck, H. D. (1985). A critical-review of the literature on acrolein toxicity. CRC Critical Reviews in Toxicology, 14(4), 309-380. doi:10.3109/ 10408448509037461

Brand-Williams, W., Cuvelier, M., \& Berset, C. (1995). Use of a free radical method to evaluate antioxidant activity. $L W T$ - Food Science and Technology, 2(1), 25-30. doi:10. 1016/S0023-6438(95)80008-5

Carapinha, P. G. (2012). Utilização do azeite na fritura de alimentos (Master's thesis).

Caruso, D., Berra, B., Giavarini, F., Cortesi, N., Fedeli, E., \& Galli, G. (1999). Effect of virgin olive oil phenolic compounds on in vitro oxidation of human low density lipoproteins. Nutrition Metabolism and Cardiovascular Diseases, 9(3), 102-107.

Cicerale, S., Conlan, X. A., Sinclair, A. J., \& Keast, R. S. J. (2009). Chemistry and health of olive oil phenolics. Critical Reviews in Food Science and Nutrition, $49(3)$, 218-236. doi:10.1080/10408390701856223

Codex. (2015). Standard for olive oils and olive pomace oils. (Vol. Codex Stan 33-1981). Retrieved from www . fao . org / input / download / standards / 88 / CXS_033e_2015. pdf

Daskalaki, D., Kefi, G., Kotsiou, K., \& TasioulaMargari, M. (2009). Evaluation of phenolic compounds degradation in virgin olive oil during storage and heating. Journal of Food and Nutrition Research, 48(1), 31-41.

Dobarganes, M. C. (1992). Comportamiento del aceite de oliva en la fritura de alimentos. 
Centro de Investiagación Y Control de la Calidade, 10, 19-28.

Fitó, M., de la Torre, R., Farré-Albaladejo, M., Khymenetz, O., Marrugat, J., \& Covas, M.-I. (2007). Bioavailability and antioxidant effects of olive oil phenolic compounds in humans: a review. Annali Dell'istituto Superiore Di Sanita, 43(4), 375-381. Retrieved from http:// www. iss.it/publ/ anna/2007/4/434375.pdf

Freire, P. C. M., Ferreira, T. A. P. d. C., \& Mancini-Filho, J. (2013). Principais alterações físico-químicas em óleos e gorduras submetidos ao processo de fritura por imersão: regulamentação e efeitos na saúde. Revista de Nutrição, 26 (3), 353-358.

Guasch-Ferre, M., Hu, F. B., Martinez-Gonzalez, M. A., Fito, M., Bullo, M., Estruch, R., ... Salas-Salvado, J. (2014). Olive oil intake and risk of cardiovascular disease and mortality in the predimed study. $B M C$ Medicine, 12. doi:10.1186/1741-7015-12-78

Kalantzakis, G., Blekas, G., Pegklidou, K., \& Boskou, D. (2006). Stability and radicalscavenging activity of heated olive oil and other vegetable oils. European Journal of Lipid Science and Technology, 108(4), 329335. doi:10.1002/ejlt.200500314

Katragadda, H. R., Fullana, A., Sidhu, S., \& Carbonell-Barrachina, A. A. (2010). Emissions of volatile aldehydes from heated cooking oils. Food Chemistry, 120(1), 5965. doi:10.1016/j.foodchem.2009.09.070

Kim, D. O., Chun, O. K., Kim, Y. J., Moon, H. Y., \& Lee, C. Y. (2003). Quantification of polyphenolics and their antioxidant capacity in fresh plums. Journal of Agricultural and Food Chemistry, 51(22), 65096515. doi:10.1021/jf0343074

Lopez-Miranda, J., Perez-Jimenez, F., Ros, E., De Caterina, R., Badimon, L., Covas, M. I., ... Yiannakouris, N. (2010). Olive oil and health: summary of the ii international conference on olive oil and health consensus report, jaen and cordoba (spain) 2008. Nutrition Metabolism and Cardiovascular Diseases, 20(4), 284-294. doi:10.1016/j . numecd.2009.12.007

Nogueira-de-Almeida, C. A., Ribas Filho, D., de Mello, E. D., Melz, G., \& Almeida, A. C. F.
(2015). Azeite de oliva e suas propriedades em preparações quentes: revisão da literatura. International Journal of Nutrology, $8(2), 13-20$.

Nunes, C. A., de Souza, V. R., Correa, S. C., \& da Costa e Silva, M. d. C. (2013). Heating on the volatile composition and sensory aspects of extra-virgin olive oil. Ciencia $E$ Agrotecnologia, 37(6), 566-572.

Owen, R. W., Giacosa, A., Hull, W. E., Haubner, R., Wurtele, G., Spiegelhalder, B., \& Bartsch, H. (2000). Olive-oil consumption and health: the possible role of antioxidants. The Lancet Oncology, 1(2), 107-112.

Papadimitriou, V., Sotiroudis, T. G., Xenakis, A., Sofikiti, N., Stavyiannoudaki, V., \& Chaniotakis, N. A. (2006). Oxidative stability and radical scavenging activity of extra virgin olive oils: an electron paramagnetic resonance spectroscopy study. Analytica Chimica Acta, 573(SI), 453-458. 4th International Conference on Instrumental Methods of Analysis, Iraklion, GREECE, OCT 02-06, 2005. doi:10.1016/j.aca. 2006. 02.007

Penz, L. R. (2010). Estudo das alterações físicoquímicas do azeite de oliva após tratamento térmico (Master's thesis, UNIVATES, Lajeado, RS). Retrieved from http:// hdl. handle.net/10737/102

Ragazzi, E. \& Veronese, G. (1973). Quantitativeanalysis of phenolic compounds after thinlayer chromatographic separation. Journal of Chromatography, 77(2), 369-375. doi:10. 1016/S0021-9673(00)92204-0

Sacchi, R., Paduano, A., Savarese, M., Vitaglione, P., \& Fogliano, V. (2014). Extra virgin olive oil: from composition to "molecular gastronomy". In V. Zappia, S. Panico, G. L. Russo, A. Budillon, \& F. Della Ragione (Eds.), Advances in nutrition and cancer (pp. 325-338). Berlin, Heidelberg: Springer Berlin Heidelberg. doi:10.1007/978-3-642-38007-5_19

Sanchez-Gimeno, A. C., Negueruela, A. I., Benito, M., Vercet, A., \& Oria, R. (2008). Some physical changes in bajo aragon extra virgin olive oil during the frying process. Food Chemistry, 110(3), 654-658. doi:10.1016/j. foodchem.2008.02.057 
Effects of heat treatment on olive oil $\mid 99$

Sánchez-Muniz, F. J. \& Bastida, S. (2006). Effect of frying and thermal oxidation on olive oil and food quality. Olive oil and health, 74108.

Santos, C. S. P., Cruz, R., Cunha, S. C., \& Casal, S. (2013). Effect of cooking on olive oil quality attributes. Food Research International, 54(2), 2016-2024. doi:10.1016/j . foodres.2013.04.014

Schwingshackl, L., Christoph, M., \& Hoffmann, G. (2015). Effects of olive oil on markers of inflammation and endothelial function-a systematic review and meta-analysis. $\mathrm{Nu}$ trients, 7(9), 7651-7675. doi:10.3390/ nu7095356

Schwingshackl, L. \& Hoffmann, G. (2014a). Mediterranean dietary pattern, inflammation and endothelial function: a systematic review and meta-analysis of intervention trials. Nutrition Metabolism and Cardiovascular Diseases, 24(9), 929-939. doi:10. 1016/j.numecd.2014.03.003

Schwingshackl, L. \& Hoffmann, G. (2014b). Monounsaturated fatty acids, olive oil and health status: a systematic review and meta-analysis of cohort studies. Lipids in Health and Disease, 13. doi:10.1186/1476511X-13-154

Shahidi, F. \& Zhong, Y. (2005). Antioxidants: regulatory status. Bailey's Industrial Oil and Fat Products.

Valderas-Martinez, P., Chiva-Blanch, G., Casas, R., Arranz, S., Martinez-Huelamo, M., Urpi-Sarda, M., ... Estruch, R. (2016). Tomato sauce enriched with olive oil exerts greater effects on cardiovascular disease risk factors than raw tomato and tomato sauce: a randomized trial. Nutrients, $8(3)$. doi:10.3390/nu8030170 